\title{
Comparison of visual evoked potentials and retinal nerve fiber layer thickness in Alzheimer's disease
}

\section{Robert Kromer ${ }^{1}$, Nermin Serbecic ${ }^{1}$, Lucrezia Hausner ${ }^{2}$, Lutz Froelich ${ }^{2}$ and Sven C. Beutelspacher ${ }^{1}$ *}

' Department of Ophthalmology, Medical Faculty Mannheim, Ruprecht-Karls-University Heidelberg, Mannheim, Germany

2 Division of Geriatric Psychiatry, Central Institute of Mental Health, Medical Faculty Mannheim, Ruprecht-Karls-University Heidelberg, Mannheim, Germany

\section{Edited by:}

Ritchie Williamson, University of

Dundee, UK

Reviewed by:

Gareth R. Howell, The Jackson Laboratory, USA

Karen Hampson, University of

Bradford, UK

${ }^{*}$ Correspondence:

Sven C. Beutelspacher, Department of Ophthalmology, Medical Faculty Mannheim, Ruprecht-Karls-University Heidelberg, Theodor-Kutzer-Ufer 1-3, 68167 Mannheim, Germany

e-mail: beutelspacher@

urz.uni-heidelberg.de

Introduction: Alzheimer's disease (AD) is a long term progressive neurodegenerative disease and might affect the retinal nerve fiber layer thickness (RNFLT) of the eye. There is increasing evidence that visual evoked potentials (VEP), which are an objective way to indicate visual field loss, might be affected by the disease as well.

Materials and Methods: About 22 patients (mean age: $75.9 \pm 6.1$ years; 14 women) with mild-to-moderate $A D$ and 22 sex-matched healthy patients were examined. We compared the use of VEP and RNFLT using the latest high-resolution spectral domain optical coherence tomography with eye-tracking capabilities for optimized peripapillary scan centering for the first time in AD patients.

Results: The mean MMSE score was $22.59 \pm 5.47$ in the AD group, and did not significantly correlate with the VEP latencies. We found no significant difference between the VEP latencies of the AD patients and those of the control patients. No peripapillary sector of the retina had a RNFLT significantly correlated with the VEP latencies.

Discussion: We demonstrated that pattern VEP did not show any significant correlation despite subtle loss in RNFLT. It remains open whether additional flash VEP combined with RNFLT analysis may be useful in diagnosing $A D$, particularly for mild-to-moderate stages of the disease.

Keywords: Alzheimer's disease, dementia, retinal nerve fiber layer thickness, visual evoked potentials, optical coherence tomography

\section{INTRODUCTION}

Alzheimer's disease $(\mathrm{AD})$ is described as a long term progressive neurodegenerative disease and characterized by a large intersubject variability. The pathogenesis of $\mathrm{AD}$ is still an open debate. In most cases, the clinical diagnosis of $\mathrm{AD}$ is made early enough and is accurate, however paraclinical support would be useful for all cases, and even more so if the disease course, namely neurodegenerative changes and therapeutic effects, could be monitored and objectified over time. Drugs which have been used for the therapy of AD might be most effective in the early stages of the disease (1). Traditional neuro-imaging diagnostics including magnetic resonance imaging (MRI) to show the atrophy of the medial temporal lobe $(2,3)$, positron emission tomography (PET) to detect changes in the metabolism of glucose $(3,4)$ and the $A \beta$ storage $(5,6)$, and the cerebrospinal fluid analysis (CSA) to measure the biomarkers for tau protein and $\mathrm{A} \beta$ levels $(7,8)$ have only limited value (9).

A new ophthalmic imaging method called optical coherence tomography (OCT) has been considered to be useful for the detection of early stages of $\mathrm{AD}(10-12)$. OCT provides cross-section imaging of the retina and is able to measure the retinal nerve fiber layer thickness (RNFLT) $(13,14)$. It has been used for the diagnosis of many diseases of the retina and various optic neuropathies, including glaucoma (15-22). The human eye is an embryological protrusion of the brain, and the nerves and axons of the retinal nerve fiber layer are similar to those of the brain. This leads to the question of whether AD might also affect the RNFLT of the eye. For many years histopathological studies have shown that the RNFLT is not affected by $\operatorname{AD}(23,24)$. In contrast to this, recent OCT studies, claimed to be able to detect a loss of the RNFLT in patients with $\operatorname{AD}(11,12,25-27)$. However, those studies were performed using conventional OCT technology, lacking reliable optic nerve scan centering (21), a subject to potential misinterpretation in a number of cases (21). Studies showed that OCT measurements of the RNFLT were associated with mild cognitive impairment (MCI), and this could be taken to discriminate between different stages of $\mathrm{AD}(10-12)$.

Visual evoked potentials (VEP) are an objective way to indicate visual field loss (28-31). They represent the visual cortex activity, as they are a reaction to the visual information that is passing through the optical media of the eye which gets processed by the retina and the genicula-striate pathway. The occurring evoked response shows the performance of the visual system until that point. There are numerous studies discussing the use of VEP in AD. Some studies have shown that $\mathrm{AD}$ patients have longer latencies of flash VEP (32-34). Contrary to this, other studies showed normal pattern VEP while the RNFLT, as measured with conventional OCT technology, presented abnormal in $\mathrm{AD}$ patients (11). 
The purpose of this study was to compare the use of VEP and RNFLT using the latest high-resolution spectral domain optical coherence tomography (SD-OCT) with eye-tracking capabilities for optimized peripapillary scan centering for the first time in $\mathrm{AD}$ patients. The goals were to show (i) whether there is any change of VEP in AD patients as compared to sex-matched controls, and (ii) to correlate those latencies with the RNFLT of the AD patients.

\section{MATERIALS AND METHODS}

About 42 eyes of 22 patients (mean age: $75.9 \pm 6.1$ years; 14 women) with mild-to-moderate $\mathrm{AD}$ were examined - two patients had only one eye examined. The control group involved 43 eyes of 22 sex-matched healthy patients (mean age: $64.0 \pm 8.2$ years; 15 women) - one patient had only one eye examined. The study was approved by the Ethics committee II of the Medical Faculty Mannheim, Ruprecht-Karls-University Heidelberg, Mannheim, Germany and followed the ethical principles of the Declaration of Helsinki. Before the examinations, informed consent was obtained from each patient. In case the patient was incompetent of giving informed consent, the care giver (spouse or adult child) declared their approval.

Alzheimer's disease was diagnosed by a physician and a multiprofessional team (neurologists, psychiatrists, psychologists) at the Memory Clinic of the Department of Geriatric Psychiatry of the Central Institute of Mental Health, Mannheim, Germany. The assessments consisted of the medical history from the patient and caregiver, general exams, laboratory, neuropsychological, and radiologic tests. To indicate progressive cognitive decline of everyday functioning and to show the absence of any neurological or psychiatric disorder possibly causing dementia (other than AD) general physical, neurological, and neuropsychological examinations were performed. The laboratory testing included complete blood count with differential counts, syphilis screening, serum electrolytes, liver and renal function, cholesterol status, thyroid function, serum vitamin B12, and folate levels. This way secondary causes of dementia were excluded. The neuropsychological tests (CERAD test battery WMS-LM, TMT-A and -B) were used to show an impairment in one or two more clinical domains severe enough to cause impairment in activities of daily life. For radiologic testing MRI was used to show a visual rating of evidence of medial temporal lobe atrophy and absence of major white matter abnormalities and/or other cerebrovascular disorders. In addition to that most patients had lowered $A \beta 42$ peptide and accelerated tau and/or phospho-tau in cerebrospinal fluid (which is typical for AD).

The patients' history and medical records were carefully reviewed for diseases possibly affecting the RNFLT. Only patients meeting inclusion and exclusion criteria were included. The ophthalmic inclusion criteria were (i) best-corrected visual acuity of 0.3 LogMAR or better, (ii) spherical refraction within \pm 5.0 diopters (D), (iii) cylindrical correction within $\pm 2.0 \mathrm{D}$, and (iv) normal results for visual field testing (Swedish Interactive Thresholding Algorithm SITA; Octopus 101 Perimeter; HaagStreit Deutschland GmbH, Wedel, Germany). The exclusion criteria were (i) intensive alcohol abuse, (ii) body mass index $>30$, (iii) intraocular pressure $\geq 21 \mathrm{mmHg}$, (iv) history of glaucoma, (v) anterior ischemic optic neuropathy, (vi) high myopia, (vii) prior ocular surgery, and (viii) congenital abnormal abnormalities of the optic nerve.

Patients underwent various ophthalmic examinations: (i) assessment of best-corrected visual acuity by auto-refractometry (OCULUS/NIDEK auto-refractometer, OCULUS Optikgeräte $\mathrm{GmbH}$, Wetzlar, Germany) followed by subjective refractometry using the ETDRS (Early Treatment of Diabetic Retinopathy Study) 2000 chart for high-contrast visual acuity, (ii) slit lamp assisted biomicroscopy of the anterior segment, (iii) ophthalmoscopy after medical dilation of the pupil, (iv) visual field testing (Swedish Interactive Thresholding Algorithm SITA; Octopus 101 Perimeter; Haag-Streit Deutschland GmbH, Wedel, Germany), (v) Goldmann applanation tonometry, (vi) VEP measurement, (vii) OCT for RNFLT measurement.

The VEP were carried out with ROLAND CONSULT RETIport/scan 21 (ROLAND CONSULT, Brandenburg an der Havel, Deutschland) in abidance of the current guideline for pattern VEP of the International Society for Clinical Electrophysiology of Vision (35). The pattern-reversal protocol used black and white checks changing phase abruptly and repeatedly at a reversal rate of two reversals per second $( \pm 10 \%)$ (Each full cycle consists of two reversals so this equates a frequency of $1.0 \mathrm{~Hz}$.). The checkerboard stimuli with large $1^{\circ}\left(60 \mathrm{~min}\right.$ of arc) and small $0.25^{\circ}(15 \mathrm{~min})$ checks provided N75 and P100 peaks, where P100 peaks are the most prominent ones.

The thickness of the RNFLT was measured using latest highresolution SD-OCT (SPECTRALIS software version 5.3.3.0, EYE EXPLORER Software 1.6.4.0; Heidelberg Engineering, Heidelberg, Germany). This device is a combination of normal SD-OCT and confocal scanning laser ophthalmoscopy (cSLO). The superluminescence diode of the SD-OCT emits a scan beam with a wavelength of $879 \mathrm{~nm}$ performing up to $40,000 \mathrm{~A}$-scans/s with a depth resolution of $7 \mu \mathrm{m}$ and a transversal resolution of $14 \mu \mathrm{m}$. The cSLO scans point to point with a laser the illuminated retina and creates this way a real-time reference fundus image. SD-OCT examinations are fast, inexpensive, objective, and non-dependent on the cooperation of patient. The SD-OCT has several additional features that were used in this study: eye-tracking (TrueTrack ${ }^{\mathrm{TM}}$; Heidelberg Engineering, Heidelberg, Germany) locks the SD-OCT image to the reference fundus capture and enables comparing repeated measurements. Furthermore, the examination is nondependent on the investigator due to the enabled eye-tracking. The automatic real-time averaging mode (ART) takes additional $\mathrm{B}$ scans in order to improve the quality. Therefore, the device locks after the first A scan and adds B scans whenever the eye has the exact same position. These two features combined with the high speed of the device facilitate reducing artifacts. In our study at least three high-resolution images with enabled ART mode (with at least 18 additional frames) were taken. Scans with low fixation or failing RNFL segmentation were excluded. To minimize possible variabilities, all images were performed by one examiner. The criteria for determining the scan quality were: (i) a clear fundus image before and after the acquisition; (ii) absence of scan or algorithm failures; (iii) even and dense gray scale saturation in all retinal layers and dense gray visible in retinal pigment epithelium; and (iv) RNFL visible as a continuous scan pattern. 


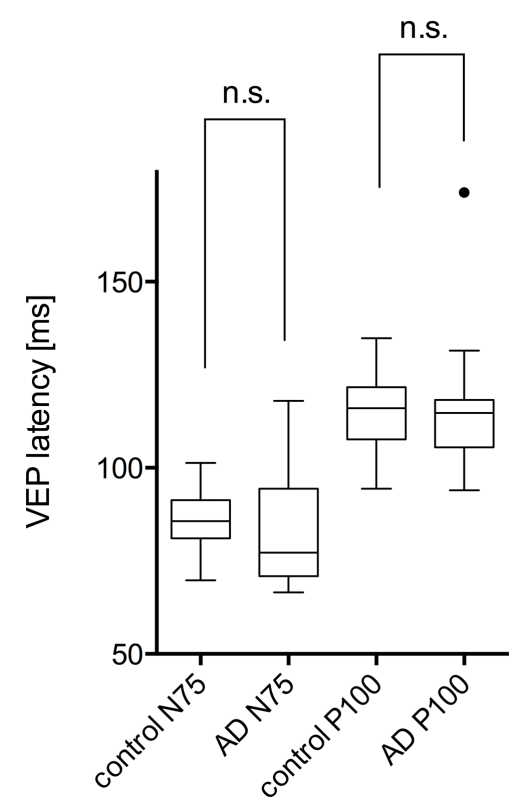

FIGURE 1 | Comparison of VEP latencies (N75 and P100) of control patients (marked as control) and AD patients (marked as AD). No significant (marked as n.s.) differences were found between the two groups ( $P$-value $>0.05)$. Data is presented as a Tukey box-and-whiskers plot, with values that are above or below the whiskers drawn as individual dots.

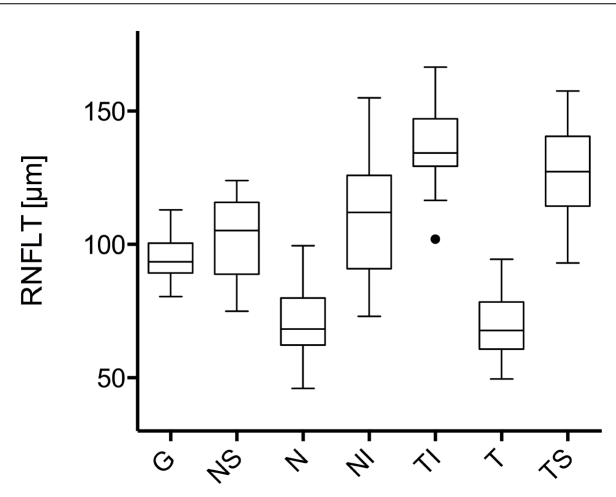

FIGURE 2 | Comparison of the retinal nerve fiber layer thickness in different peripapillary sectors: the different sectors are labeled as follows: global (G), nasal superior (NS), nasal (N), nasal inferior (NI), temporal inferior (TI), temporal (T), and temporal superior (TS). Data is presented as a Tukey box-and-whiskers plot, with values that are above or below the whiskers drawn as individual dots.

Statistical analysis was carried out using a commercially available software package (Prism 6 for Mac OSX; GraphPad Software, Version 6.0b). Mean and standard deviations were presented. $P$-values were corrected according to Bonferroni to correct for performing multiple statistical analyses. All $P$-values were twotailed and a $P$-value $<0.05$ was considered to indicate statistical significance. Correlation was done using Pearson correlation calculations as values are sampled from populations that

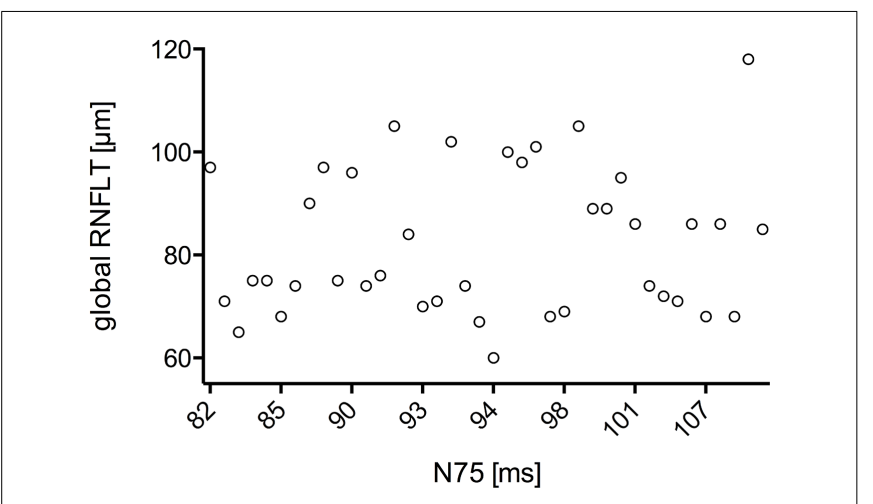

FIGURE 3 | Scatter plot of all N75 latencies in dependence of the associated global RNFLT. There was no significant correlation found for N75 latency with global RNFLT in AD patients ( $r=0.271$; $P$-value $=0.222$ ).

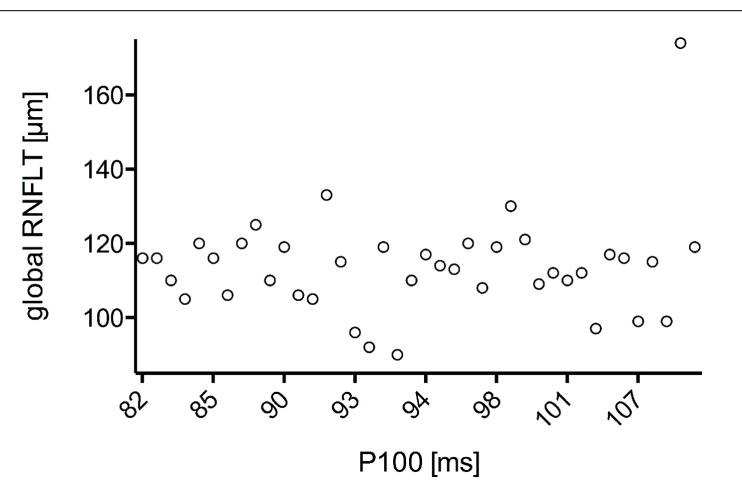

FIGURE 4 | Scatter plot of all P100 latencies in dependence of the associated global RNFLT. There was no significant correlation found for N75 latency with global RNFLT in AD patients $(r=0.322$; $P$-value $=0.144$ ).

follow a Gaussian distribution - at least approximately. By correlation coefficient $r$ is meant. VEP comparison and RNFLT are presented as Tukey box-and-whiskers plots with values that are above or below the whiskers drawn as individual dots. The mean of both eyes of each participant was used for statistical analysis (phenotype). VEP normative data standardization was established following the guidelines of the International Society for Clinical Electrophysiology of Vision (35), resulting in a $95 \%$ reference interval as the limit of normal (range from 2.5 to $97.5 \%)$.

\section{RESULTS}

The study included 42 eyes of 22 patients with AD (mean age: $75.9 \pm 6.1$ years; age range: $66-88$ years; 14 women), and 43 eyes of 22 sex-matched healthy control patients (mean age: $64.0 \pm 8.2$ years; age range: $53-85$ years; 16 women). In both groups, there was no significant correlation found between male or female and the right or left eye in RNFLT and VEP latencies $(P$ value $>0.05$ ). There was no significant correlation of VEP latencies and RNFLT with the age of the participants in both groups. The mean MMSE score was 22.59 \pm 5.47 in the AD group, and this was not significantly correlated with the VEP latencies. We found 
Table 1 | Correlation of N75 and P100 latencies with the RNFLT of the different sectors.

\begin{tabular}{|c|c|c|c|c|c|c|c|}
\hline & G & NS & $\mathbf{N}$ & NI & TI & $\mathbf{T}$ & TS \\
\hline N75 & $0.271 P=0.222$ & $0.363 P=0.096$ & $0.344 P=0.117$ & $-0.027 P=0.905$ & $0.091 P=0.689$ & $0.068 P=0.763$ & $0.139 P=0.537$ \\
\hline P100 & $0.322 P=0.144$ & $0.194 P=0.386$ & $0.359 P=0.101$ & $0.261 P=0.242$ & $0.155 P=0.491$ & $0.015 P=0.946$ & $0.145 P=0.519$ \\
\hline
\end{tabular}

The different sectors are labeled as follows: global (G), nasal superior (NS), nasal (N), nasal inferior (NI), temporal inferior (TI), temporal (T), and temporal superior (TS). The correlation tests with Bonferroni correction for multiple comparisons showed no significant correlations. The table shows the correlation coefficients and the $P$-value below. A P-value $<0.05$ is considered significant (with Bonferroni correction for multiple comparison in this case a P-value $<0.0036$ is considered significant).

no significant difference between the VEP latencies of the AD patients and those of the control patients $(P$-value $>0.05)$, as presented in Figure 1. Furthermore, all AD patients had normal VEP values within the $95 \%$ reference interval as the limit of normal (range from 2.5 to $97.5 \%$ ). The RNFLT of the AD patients is presented in Figure 2. Using our previously introduced advanced gender-matched measurement model, the RNFLT was marked as pathologic in 32 out of 42 eyes (76.19\%) (36). In order to show the relationship between VEP latencies and RNFLT of the AD patients globally, we outlined two scatter plots (Figures 3 and 4). No correlation was found between these variables. In more detail, no peripapillary sector of the retina had a RNFLT that significantly correlated with the VEP latencies (Table 1; $P$-value $>0.05$ ).

\section{DISCUSSION}

Our results showed normal pattern VEP latencies compared to a sex-matched healthy control group. Furthermore, the RNFLT of the AD patients did not correlate with pattern VEP latencies.

The use of VEP in AD has been discussed a lot in recent years. Some studies found abnormal pattern VEP in AD patients (33, $37,38)$. In contrast, a number of authors stated that they did not find any abnormalities in pattern VEP while experiencing abnormal flash VEP (39-43). Nevertheless, flash VEP suffer from a lower reproducibility compared to pattern VEP (35). One study comparing RNFLT and VEP in AD found normal pattern VEP with abnormal RNFLT, however using conventional OCT technology (11). The RNFLT has been examined in several studies using histopathologic techniques, with inconsistent findings. Some stated that there is no decrease (44-48), while others found abnormal RNFLT (23, 24). Additionally, studies using conventional time-domain OCT technology, lacking eye-tracking capabilities, found only a subtle RNFLT decrease in AD patients (10-12, 25, 49-51).

The different findings between flash and pattern VEP may result from the different methodological approach. The functional organization of the proximal retina and the visual cortex is preferentially sensitive to patterned stimuli (52). As the changes in RNFLT are mostly subtle and/or subclinical, there may be no effect in pattern VEP while experiencing abnormal flash VEP. The disagreement in OCT studies may also evolve from divergent stages of the disease and the technical inaccuracy of postmortem histopathological studies. In our case all AD patients had a mild-to-moderate AD.

Our results implicate that pattern VEP does not show any changes in AD despite the fact that RNFLT changes demonstrated as a decrease in one or more peripapillary sectors, were found in some but not all $\mathrm{AD}$ patients. As a consequence, pattern VEP did not correlate with the RNFLT of AD patients. However, severe stages of the disease may show further changes. Nevertheless, literature indicates that the use of flash VEP may be recommended to show changes in $\mathrm{AD}$.

The limitations of this study were, (i) that no flash VEP was used to show the difference to pattern VEP, (ii) that only cross-sectional measurements were done without follow-up to investigate a potential progression of the RNFLT and VEP, and (iii) that the patients had a mild-to-moderate AD. On the other hand, the strengths were that (i) patients and controls were sex-matched, (ii) for the first time latest high-resolution SD-OCT measurements were obtained, and (iii) the clinical diagnosis of $\mathrm{AD}$ was obtained in a specialized memory clinic by using highly standardized clinical criteria, including neuropsychological assessments and biomarkers (MTA, CSF).

In summary, we demonstrated that pattern VEP may not be useful for diagnosing $\mathrm{AD}$ and may not show a correlation despite subtle loss in RNFLT. It remains unclear whether flash VEP combined with RNFLT analysis may be useful in diagnosing AD, taken in account that flash VEP have a lower reproducibility compared to pattern VEP. For further studies, it is important for the interpretation of SD-OCT- and VEP-investigations that the standardized technical requirements provided by latest SD-OCT technology are used and the current guidelines are applied.

\section{REFERENCES}

1. Guo L, Salt TE, Maass A, Luong V, Moss SE, Fitzke FW, et al. Assessment of neuroprotective effects of glutamate modulation on glaucoma-related retinal ganglion cell apoptosis in vivo. Invest Ophthalmol Vis Sci (2006) 47:626-33. doi:10.1167/iovs.05-0754

2. Jagust WJ, Gitcho A, Sun F, Kuczynski B, Mungas D, Haan M. Brain imaging evidence of preclinical Alzheimer's disease in normal aging. Ann Neurol (2006) 59:673-81. doi:10.1002/ana.20799

3. Davatzikos C, Resnick SM, Wu X, Parmpi P, Clark CM. Individual patient diagnosis of AD and FTD via high-dimensional pattern classification of MRI. Neuroimage (2008) 41:1220-7. doi:10.1016/j.neuroimage.2008.03.050

4. Jagust WJ, Seab JP, Huesman RH, Valk PE, Mathis CA, Reed BR, et al. Diminished glucose transport in Alzheimer's disease: dynamic PET studies. J Cereb Blood Flow Metab (1991) 11:323-30. doi:10.1038/jcbfm.1991.65

5. Engler H, Forsberg A, Almkvist O, Blomquist G, Larsson E, Savitcheva I, et al. Two-year follow-up of amyloid deposition in patients with Alzheimer's disease. Brain (2006) 129:2856-66. doi:10.1093/brain/awl178

6. Barrio JR, Kepe V, Satyamurthy N, Huang SC, Small G. Amyloid and tau imaging, neuronal losses and function in mild cognitive impairment. J Nutr Health Aging (2008) 12:61S-5S. doi:10.1007/BF02982589

7. Bouwman FH, Schoonenboom NSM, Verwey NA, van Elk EJ, Kok A, Blankenstein MA, et al. CSF biomarker levels in early and late onsetalzheimer's disease. Neurobiol Aging (2009) 30:1895-901. doi:10.1016/j.neurobiolaging.2008.02.007

8. Diniz BSO, Pinto Júnior JA, Forlenza OV. Do CSF total tau, phosphorylated tau, and beta-amyloid 42 help to predict progression of mild cognitive impairment 
to Alzheimer's disease? A systematic review and meta-analysis of the literature. World J Biol Psychiatry (2008) 9:172-82. doi:10.1080/15622970701535502

9. Ballard C, Gauthier S, Corbett A, Brayne C, Aarsland D, Jones E. Alzheimer's disease. Lancet (2011) 377:1019-31. doi:10.1016/S0140-6736(10)61349-9

10. Paquet C, Boissonnot M, Roger F, Dighiero P, Gil R, Hugon J. Abnormal retinal thickness in patients with mild cognitive impairment and Alzheimer's disease. Neurosci Lett (2007) 420:97-9. doi:10.1016/j.neulet.2007.02.090

11. Iseri P, Altinas $\mathrm{O}$, Tokay T, Yuksel N. Relationship between cognitive impairment and retinal morphological and visual functional abnormalities in Alzheimer disease. J Neuro-Ophthalmol (2006) 26:18-24. doi:10.1097/01.wno.0000204645. 56873.26

12. Kesler A, Vakhapova V, Korczyn AD, Naftaliev E, Neudorfer M. Retinal thickness in patients with mild cognitive impairment and Alzheimer's disease. Clin Neurol Neurosurg (2011) 113:523-6. doi:10.1016/j.clineuro.2011.02.014

13. Huang D, Swanson EA, Lin CP, Schuman JS, Stinson WG, Chang W, et al. Optical coherence tomography. Science (1991) 254:1178-81. doi:10.1126/science. 1957169

14. Schuman JS, Pedut-Kloizman T, Pakter HM, Wang N, Guedes V, Huang L, et al. Optical coherence tomography and histologic measurements of nerve fiber layer thickness in normal and glaucomatous monkey eyes. Invest Ophthalmol Vis Sci (2007) 48:3645-54. doi:10.1167/iovs.06-0876

15. Guedes V, Schuman JS, Hertzmark E, Wollstein G, Correnti A, Mancini R, et al. Optical coherence tomography measurement of macular and nerve fiber layer thickness in normal and glaucomatous human eyes. Ophthalmology (2003) 110:177-89. doi:10.1016/S0161-6420(02)01564-6

16. Hee MR, Izatt JA, Swanson EA, Huang D, Schuman JS, Lin CP, et al. Optical coherence tomography of the human retina. Arch Ophthalmol (1995) 113:325-32. doi:10.1001/archopht.1995.01100030081025

17. Hee MR, Puliafito CA, Wong C, Duker JS, Reichel E, Schuman JS, et al. Optical coherence tomography of macular holes. Ophthalmology (1995) 102:748-56. doi:10.1016/S0161-6420(95)30959-1

18. Krivoy D, Gentile R, Liebmann J, Stegman Z, Walsh J, Ritch R. Imaging congenital optic disc pits and associated maculopathy using optical coherence tomography. Arch Ophthalmol (1996) 114:165-70. doi:10.1001/archopht.1996. 01100130159008

19. Serbecic N, Beutelspacher SC, Kircher K, Reitner A, Schmidt-Erfurth U. Interpretation of RNFLT values in multiple sclerosis-associated acute optic neuritis using high-resolution SD-OCT device. Acta Ophthalmol (2012) 90(6):540-5. doi:10.1111/j.1755-3768.2010.02013.x

20. Serbecic N, Aboul-Enein FC, Beutelspacher SC, Graf M, Kircher K, Geitzenauer $\mathrm{W}$, et al. Heterogeneous pattern of retinal nerve fiber layer in multiple sclerosis. High resolution optical coherence tomography: potential and limitations. PLoS One (2010) 5:e13877. doi:10.1371/journal.pone.0013877

21. Serbecic N, Beutelspacher SC, Aboul-Enein FC, Kircher K, Reitner A, SchmidtErfurth U. Reproducibility of high-resolution optical coherence tomography measurements of the nerve fibre layer with the new Heidelberg Spectralis optical coherence tomography. Br J Ophthalmol (2011) 95:804-10. doi:10.1136/bjo. 2010.186221

22. Serbecic N, Aboul-Enein FC, Beutelspacher SC, Vass C, Kristoferitsch W, Lassmann $\mathrm{H}$, et al. High resolution spectral domain optical coherence tomography (SD-OCT) in multiple sclerosis: the first follow up study over two years. PLoS One (2011) 6:e19843. doi:10.1371/journal.pone.0019843

23. Curcio CA, Drucker DN. Retinal ganglion cells in Alzheimer's disease and aging. Ann Neurol (1993) 33:248-57. doi:10.1002/ana.410330305

24. Davies DC, McCoubrie P, McDonald B, Jobst KA. Myelinated axon number in the optic nerve is unaffected by Alzheimer's disease. Br J Ophthalmol (1995) 79:596-600. doi:10.1136/bjo.79.6.596

25. Berisha F, Feke GT, Trempe CL, McMeel JW, Schepens CL. Retinal abnormalities in early Alzheimer's disease. Invest Ophthalmol Vis Sci (2007) 48:2285-9. doi:10.1167/iovs.06-1029

26. Hedges TR, Perez Galves R, Speigelman D, Barbas NR, Peli E, Yardley CJ. Retinal nerve fiber layer abnormalities in Alzheimer's disease. Acta Ophthalmol Scan (1996) 74:271-5. doi:10.1111/j.1600-0420.1996.tb00090.x

27. Valenti DA. Neuroimaging of retinal nerve fiber layer in AD using optical coherence tomography. Neurology (2007) 69:1060. doi:10.1212/01.wnl.0000280584. 64363.83
28. Sokol S. An electrodiagnostic index of macular degeneration. Use of a checkerboard pattern stimulus. Arch Ophthalmol (1972) 88:619-24.

29. Halliday AM, McDonald WI, Mushin J. Visual evoked response in diagnosis of multiple sclerosis. Br Med J (1973) 4:661-4. doi:10.1136/bmj.4.5893.661

30. Arden GB. Proceedings: the visual evoked response in ophthalmology. Proc $R$ Soc Med (1973) 66:1037-43.

31. Bodis-Wollner I, Atkin A, Raab E, Wolkstein M. Visual association cortex and vision in man: pattern-evoked occipital potentials in a blind boy. Science (1977) 198:629-31. doi:10.1126/science.918658

32. Harding GF, Wright CE, Orwin A. Primary presenile-dementia - the use of the visual evoked-potential as a diagnostic indicator. Br J Psychiatry (1985) 147:532-9. doi:10.1192/bjp.147.5.532

33. Orwin A, Wright CE, Harding GF, Rowan DC, Rolfe EB. Serial visual evoked potential recordings in Alzheimer's disease. Br Med J (Clin Res Ed) (1986) 293:9-10. doi:10.1136/bmj.293.6538.9

34. Pollock VE, Schneider LS, Chui HC, Henderson V, Zemansky M, Sloane RB. Visual evoked-potentials in dementia - a meta-analysis and empirical-study of Alzheimers-disease patients. Biol Psychiat (1989) 25:1003-13. doi:10.1016/ 0006-3223(89)90288-6

35. Odom JV, Bach M, Brigell M, Holder GE, McCulloch DL, Tormene AP, et al. ISCEV standard for clinical visual evoked potentials (2009 update). Doc Ophthalmol (2010) 120:111-9. doi:10.1007/s10633-009-9195-4

36. Beutelspacher SC, Serbecic N, Hausner L, Kromer R, Aboul-Enein FC, Froehlich $\mathrm{L}$, et al. Detection of retinal nerve fibre layer defects in Alzheimers dementia using SD-OCT. Acta Ophthalmol (2011) 89:0-0. doi:10.1111/j.1755-3768.2011. 2262.x

37. Coben LA, Danziger WL, Hughes CP. Visual evoked potentials in mild senile dementia of Alzheimer type. Electroencephalogr Clin Neurophysiol (1983) 55:121-30. doi:10.1016/0013-4694(83)90178-5

38. Visser SL, van Tilburg W, Hooijer C, Jonker C, de Rijke W. Visual evoked potentials (VEPs) in senile dementia (Alzheimer type) and in non-organic behavioural disorders in the elderly; comparison with EEG parameters. Electroencephalogr Clin Neurophysiol (1985) 60:115-21. doi:10.1016/0013-4694(85)90017-3

39. Bajalan AA, Wright CE, van der Vliet VJ. Changes in the human visual evoked potential caused by the anticholinergic agent hyoscine hydrobromide: comparison with results in Alzheimer's disease. J Neurol Neurosurg Psychiatr (1986) 49:175-82. doi:10.1136/jnnp.49.2.175

40. Cosi V, Vitelli E, Gozzoli L, Corona A, Ceroni M, Callieco R. Visual evoked potentials in aging of the brain. Adv Neurol (1982) 32:109-15.

41. Wright CE, Drasdo N, Harding GF. Pathology of the optic nerve and visual association areas. Information given by the flash and pattern visual evoked potential, and the temporal and spatial contrast sensitivity function. Brain (1987) 110(Pt 1):107-20. doi:10.1093/brain/110.1.107

42. Wright CE, Harding GF, Orwin A. Presenile dementia - the use of the flash and pattern VEP in diagnosis. Electroencephalogr Clin Neurophysiol (1984) 57:405-15. doi:10.1016/0013-4694(84)90069-5

43. Wright CE, Harding GF, Orwin A. The flash and pattern VEP as a diagnostic indicator of dementia. Doc Ophthalmol (1986) 62:89-96. doi:10.1007/BF00140551

44. Hinton DR, Sadun AA, Blanks JC, Miller CA. Optic-nerve degeneration in Alzheimer's disease. N Engl J Med (1986) 315:485-7. doi:10.1056/ NEJM198608213150804

45. Sadun AA, Bassi CJ. Optic nerve damage in Alzheimer's disease. Ophthalmology (1990) 97:9-17. doi:10.1016/S0161-6420(90)32621-0

46. Tsai CS, Ritch R, Schwartz B, Lee SS, Miller NR, CHI T, et al. Optic-nerve head and nerve-fiber layer in Alzheimer's-disease. Arch Ophthalmol (1991) 109:199-204. doi:10.1001/archopht.1991.01080020045040

47. Blanks JC, Torigoe Y, Hinton DR, Blanks RH. Retinal pathology in Alzheimer's disease. I. Ganglion cell loss in foveal/parafoveal retina. Neurobiol Aging (1996) 17:377-84. doi:10.1016/0197-4580(96)00010-3

48. Blanks JC, Schmidt SY, Torigoe Y, Porrello KV, Hinton DR, Blanks RH. Retinal pathology in Alzheimer's disease. II. Regional neuron loss and glial changes in GCL. Neurobiol Aging (1996) 17:385-95. doi:10.1016/0197-4580(96) 00010-3

49. Parisi V, Restuccia R, Fattapposta F, Mina C, Bucci MG, Pierelli F. Morphological and functional retinal impairment in Alzheimer's disease patients. Clin Neurophysiol (2001) 112:1860-7. doi:10.1016/S1388-2457(01)00620-4 
50. Parisi V. Correlation between morphological and functional retinal impairment in patients affected by ocular hypertension, glaucoma, demyelinating optic neuritis and Alzheimer's disease. Semin Ophthalmol (2003) 18:50-7. doi:10.1080/08820530390897855

51. Lu Y, Li Z, Zhang X, Ming B, Jia J, Wang R, et al. Retinal nerve fiber layer structure abnormalities in early Alzheimer's disease: evidence in optical coherence tomography. Neurosci Lett (2010) 480:69-72. doi:10.1016/j.neulet.2010.06.006

52. Tasman W. Duane’s Ophthalmology 2012. Philadelphia: Lippincott Williams \& Wilkins (2012).

Conflict of Interest Statement: The authors declare that the research was conducted in the absence of any commercial or financial relationships that could be construed as a potential conflict of interest.
Received: 05 October 2013; paper pending published: 12 November 2013; accepted: 03 December 2013; published online: 16 December 2013.

Citation: Kromer R, Serbecic N, Hausner L, Froelich L and Beutelspacher SC (2013) Comparison of visual evoked potentials and retinal nerve fiber layer thickness in Alzheimer's disease. Front. Neurol. 4:203. doi: 10.3389/fneur.2013.00203

This article was submitted to Neurodegeneration, a section of the journal Frontiers in Neurology.

Copyright (c) 2013 Kromer, Serbecic, Hausner, Froelich and Beutelspacher. This is an open-access article distributed under the terms of the Creative Commons Attribution License (CC BY). The use, distribution or reproduction in other forums is permitted, provided the original author(s) or licensor are credited and that the original publication in this journal is cited, in accordance with accepted academic practice. No use, distribution or reproduction is permitted which does not comply with these terms. 